\title{
MEMÓRIA E TESSITURA DA NARRATIVA: UMA EXPERIÊNCIA ESCOLAR DE LEITURA
}

\author{
Ilse Leone Borgs Chaves de Oliveira ${ }^{1}$ \\ Andréa Ferreira Delgado ${ }^{2}$
}

RESUMO

A leitura do romance Menino de engenho, de José Lins do Rego, integra um conjunto de experiências pedagógicas interdisciplinares que relaciona práticas de leitura e o estudo de conteúdos históricos. Por meio de atividades que estimulam a compreensão da construção do texto literário, objetiva-se investigar as conexōes entre os mecanismos da memória e a criação literária, considerando as especificidades desse gênero discursivo. Esse trabalho, desenvolvido na $7^{\text {a }}$ série do Centro de Ensino e Pesquisa Aplicada à Educação da Universidade Federal de Goiás (Cepae/UFG), entrelaçou a abordagem da escravidão e a leitura do livro Doidinho, do mesmo autor, realizada no ano anterior. A partir do conceito de "permanência" das relaçôes sociais geradas na sociedade escravista, adaptou-se um texto de sociologia rural e elaboraram-se atividades que auxiliaram os alunos a perceber as múltiplas relações de trabalho no engenho Santa Rosa, analisando-as enquanto práticas construídas pela dependência e pela troca de favores. Para delinear as estratégias de produção discursiva da memória, realizou-se a transposição didática da crítica literária que enfoca a obra de José Lins do Rego. Elegeramse os seguintes eixos para investigar essa escrita da memória: a voz narrativa que combina memória e ficção para a composição da trama; a construção da infância e o jogo temporal na tessitura da narrativa. As atividades propostas constituem estratégias pedagógicas de análise do discurso literário, promovendo múltiplas experiências de leitura que contemplam desde a subjetividade da leitura individual, à discussão coletiva dos significados e sentidos do texto até a produção escrita que configura exercícios de interpretação da obra literária.

PAlaVRas-Chave: leitura, literatura, memória, interdisciplinaridade.

The memory and the interweaving of the narrative: a school reading experience

Abstract

The reading of Menino de engenho, by José Lins do Rego, is composed of a set of interdisciplinary pedagogical experiences which relates reading practices to the studies of historical contents. Through activities that stimulate the comprehension of a literary text making, it's aimed to investigate the connections between the memory mechanisms to literary crea-

1 Professora de Português no Centro de Ensino e Pesquisa Aplicada à Educação da Universidade Federal de Goiás e mestre em Lingüística. E-mail: ilseleone@yahoo.com.br.

2 Professora de História no Centro de Ensino e Pesquisa Aplicada à Educação da Universidade Federal de Goiás e doutora em História. E-mail: andreadelgado@uol.com.br. 
120 RevistaSoltaa Voz, v. 17, n. 2

tion, considering the specificities of this discursive gender. This work was developed in the seventh grade in Centro de Ensino e Pesquisa Aplicada à Educação of Universidade Federal de Goiás (Cepae/UFG). It interweaved the slavery approach to the reading of the book Doidinho, by the same author, which was done the previous year. Starting from the concept of "permanence" in social relations originated in the slavery society, a rural sociological text was adapted and activities were elaborated to assist the students to be aware of the multiple work relations in Santa Rosa sugar mill, analysed while practices made out of dependence and by exchanging favors. In order to delineate the estrategies of memory discursive production, a didactic transposition of the literary critic was done, which focused José Lins do Rego's book. The following axes were elected to investigate this memory writing: the narrative that combines memory and fiction in the plot, the childhood construction and the temporal play in the interweaving of the narrative. The proposed activities constitute pedagogic strategies of literary discourse analyses, promoting multiple reading experiences which encompass an individual reading subjectivity as well as a collective discussion of text meanings till the writing production that customizes exercises for the literary work comprehension.

KEY wORDs: reading, literature, memory, interdisciplinarity.

As propostas de ensino de Português e História, produzidas pelos professores do Cepae/UFG, consideram o estímulo à leitura e à escrita por meio de atividades significativas para o aluno como um dos fundamentos da educação escolar. Tal concepção nos permite implementar projetos interdisciplinares de ensino, que já se desenvolvem há quatro anos. Essa parceria instigou-nos à elaboração do projeto de pesquisa intitulado "Memória e literatura: a construção de atividades interdisciplinares", a partir do qual construímos diferentes experiências de leitura escolar, como a que vamos tomar como objeto de reflexão neste artigo. Outro projeto de pesquisa, intitulado "A prática social da leitura", de que participa uma das autoras, também contribuiu para nossa análise.

Calvino nos auxilia a problematizar a leitura escolar ao afirmar que

as leituras da juventude podem ser pouco profícuas pela impaciência, distração, inexperiência das instruçōes para o uso, inexperiência de vida. Podem ser (ao mesmo tempo) formativas no sentido de que dáo forma às experiências futuras, fornecendo modelos, recipientes, termos de comparação, esquemas de classificação, escalas de valores, paradigmas de beleza: todas, coisas que continuam a valer mesmo que nos recordemos pouco ou nada do livro lido na juventude (Calvino, 1997, p. 10).

Este é um dos desafios instigantes que a leitura literária nos propõe: pensar e operacionalizar recursos que façam dessa leitura algo significativo 
para os jovens estudantes, mormente para aqueles, talvez a maioria, que não teriam acesso à literatura, a não ser no espaço escolar.

O desafio maior em uma sala de aula de Português, hoje mais do que nunca, é, certamente, promover a aproximação entre o aluno-leitor e o texto literário. Maior desafio ainda é alcançar que essa aproximação resulte em uma leitura significativa, que parta da experiência subjetiva do leitor e passe pela discussão coletiva dos significados e sentidos do texto, para se chegar à produção escrita, momento em que se configuram exercícios de interpretação da obra literária. Por outro lado, nas aulas de História, não é menor desafio estimular a compreensão do passado associado às vivências de homens e mulheres, não apenas como sucessão de fatos históricos desencarnados de seus protagonistas.

Esse conjunto de desafios estimulou-nos a propor experiências pedagógicas de leitura de obras cuja trama construísse o passado a partir da trajetória de vida do autor. Por isso a escolha do objeto "memória e literatura" e o interesse em problematizar o conceito de memória em suas diferentes dimensōes: a biográfica, a coletiva, a familiar.

A história e a literatura trabalham o passado, cada uma a seu modo. Se os conteúdos históricos parecem ter pouco que ver com os alunos, pois não fomentam a curiosidade, a surpresa e o espanto diante da descoberta do modo como homens e mulheres viveram há muitos anos, a literatura possibilita aos estudantes entrar em contato com o passado por meio de personagens que têm nome próprio e histórias singulares. Desse modo, a literatura envolve mais facilmente os alunos pelo enredo que os aproxima das experiências vividas em outros tempos.

No início do ano letivo, durante o momento a que chamamos "Semana de planejamento", nós, professoras de Português e de História, nos reunimos para, entre outras atividades, selecionar as obras literárias que atendam aos propósitos do nosso projeto, que sejam adequadas à série e que sejam representativas na produção literária brasileira ou universal. A seleção e a abordagem dessas obras são orientadas por determinados eixos temáticos que se relacionam com a experiência social dos alunos e alunas. O que se pretende é problematizar o presente por meio da reflexão sobre o passado, induzida tanto pela literatura quanto pela história.

O discurso literário autobiográfico e memorialístico constrói o passado a partir das vivências cotidianas das personagens, permitindo ao aluno-leitor perceber os significados atribuídos, em outros tempos, às práticas 


\section{RevistaSoltaa Voz, v. 17, n. 2}

culturais da alimentação, do trabalho, do vestuário, da educação, da sexualidade, entre outras. O cotidiano também é objeto do discurso historiográfico produzido a partir do referencial teórico da história cultural (Certeau, 1994; Certeau, Giard e Mayol,1996; Hunt, 1992; Le Goff, 1990).

Nosso desafio é, portanto, promover a interdisciplinaridade e associar o discurso literário ao histórico para estabelecer múltiplas conexões entre presente e passado, de modo que a análise dos eixos temáticos seja também significativa para a reflexão acerca dos interesses, desejos e expectativas que marcam a adolescência.

Para desenvolver as propostas de atividades interdisciplinares, trabalhamos com as mesmas turmas pelo menos dois anos consecutivos. A experiência de leitura, objeto de reflexão neste artigo, foi realizada em duas turmas de $7^{a}$ série do Ensino Fundamental, que acompanhamos desde a série anterior.

Buscando atender alguns de nossos pressupostos teóricos, propusemos, aos alunos, a leitura, discussão e análise do livro Doidinho, o segundo da série chamada de "romance do açúcar", de José Lins do Rego (1994). Uma narrativa memorialística, de caráter autobiográfico, feita na perspectiva de um pré-adolescente que é levado a estudar em um internato, no início do século XX. A escolha de Doidinho baseou-se nos critérios apresentados, mas, também, justificou-se por possibilitar a problematização do cotidiano escolar do passado em relação ao do presente - objeto do projeto de ensino que deu início às atividades de Português e História em 2005. Vale ressaltar que a leitura literária se associa a uma série de atividades interdisciplinares, cuja metodologia fundamenta-se no trabalho com diversos gêneros discursivos que possibilitem o estudo do tema em questão, num constante diálogo entre presente-passado-presente.

Em 2006, na $7^{a}$ série, indicamos para leitura Menino de engenho (Rego, 2003 ), o primeiro dos romances do açúcar, do mesmo autor. Poderse-ia questionar a inversão na ordem dessas leituras. Por ora, basta saber que essa inversão foi determinada pelos projetos que delineamos para os dois anos de trabalho com as turmas. E, pelos depoimentos dos alunos, tanto houve os que entenderam mais o Doidinho - e por isso gostaram mais dele - quanto houve os que acharam melhor e mais fácil ler Menino de engenho. A leitura deste é a experiência que será focalizada neste trabalho.

A leitura de Menino de engenho também foi problematizada a partir de outra experiência escolar prévia dos alunos, construída em 2005, ao 
longo do desenvolvimento de outro projeto de ensino que diz respeito a um conteúdo mais específico da História, a escravidão no Brasil. Mais uma vez estabeleceu-se a relação presente-passado-presente por meio da leitura de outros gêneros discursivos que não apenas o literário ou o historiográfico - como, por exemplo, a leitura de reportagens de jornal e a análise de charges que tematizam o trabalho escravo no Brasil atual. Procuramos, assim, propor abordagens contemporâneas para o assunto em questão e, deste modo, possibilitar aos alunos uma construção de sentidos mais efetiva. Integrando esse trabalho, buscando a percepção das representações sociais da sociedade escravista, os alunos leram, discutiram, analisaram e relacionaram, com os textos do livro didático de História, o romance $A$ escrava Isaura, de Bernardo Guimarães (2000).

Além dos objetivos didáticos associados ao conteúdo de história, com a leitura de Doidinho e de Menino de engenho, temos um propósito principal: pretendemos investigar a criação literária, considerando as especificidades da escrita da memória (Delgado, 2003), contribuindo para a reflexão acerca da produção discursiva da memória e do estatuto do autor na literatura.

As estratégias discursivas de construção da memória no gênero narrativo constituem objetos privilegiados do estudo das pesquisadoras, da elaboração dos materiais didáticos e das atividades, para que os alunos compreendam que cada texto literário traz, em sua materialidade lingüística, recursos e marcas que o diferenciam dos demais, produzindo o passado a partir da subjetividade do autor.

Assim como Bosi (2003, p. 23-24), acreditamos que "existe, dentro da história cronológica, outra história mais densa de substância memorativa no fluxo do tempo. Aparece com clareza nas biografias; tal como nas paisagens; há marcos no espaço onde os valores se adensam". Os dois romances em questão permitiram-nos aproximar os alunos-leitores de obras de caráter autobiográfico e memorialístico, para procurar essa história subjetiva tecida pelos fios da memória.

Reconhecemos a resistência da literatura, arte por natureza, à pedagogização. Concordamos com Jorge Larrosa que

talvez o antipedagogismo da literatura, sua resistência à subordinação, não seja tanto uma rebelião contra a comunicação, mas contra toda a pretensão de fechar a interpetação do texto ou de centrá-lo em torno de um signifi- 
124 Revista Soltaa Voz, v. 17, n. 2

cado doutrinário e unívoco; não tanto uma revolta contra o sentido, mas contra toda pretensão de solidificação do sentido; não tanto uma negativa à representação ou ao realismo, mas a todo realismo que não problematiza o método da representação; não tanto um abandono da ética da transmissão, mas de todas as formas de transmissão que não são éticas justamente porque dão como já sabido ou já pensado aquilo que se transmite; não tanto um rechaço aos valores morais, mas a toda essa moral conformista e fingida de boa consciência na qual se refugiam os moralistas; não tanto uma separação da existência humana concreta, mas de todas essas formas de conduzir a existência humana sem inquietá-la, sem colocá-la em questão, sem levá-la além de si mesma (Larrosa, 2000, p. 128).

Por isso mesmo, ao construirmos essa experiência pedagógica, operacionalizamos com dupla dimensão: o processo de leitura das obras literárias - momento da descoberta do passado construído pelo olhar subjetivo do autor - compreende também o estudo, a reflexão e a problematização do contexto histórico no qual a trama se desenrola e adquire sentidos e significados para a história e para a memória coletiva.

Como nosso trabalho se realiza no espaço escolar, consideramos a perspectiva epistemológica da interdisciplinaridade e também propomos uma abordagem da memória que transforme o conhecimento produzido nas diferentes disciplinas acadêmicas em objeto de ensino. Portanto, um conjunto de procedimentos didáticos e metodológicos, além de questôes pertinentes à teoria da aprendizagem, são levados em conta no processo de formação das disciplinas escolares (Chervel, 1990), no qual se articulam os elementos teóricos advindos da produção científica com o fazer pedagógico.

Chevallard (1991), ao trabalhar a noção de transposição didática, enfatiza o papel do professor na criação do saber escolar. Geralmente ausente do campo científico que produz o "saber sábio" ou "saber de referência", o professor torna-se peça fundamental da transformação desse conhecimento em "saber ensinado", aquele que se efetiva em sala de aula, na relação entre o professor e os alunos, sob interferência das múltiplas variáveis do espaço escolar: o "saber a ensinar", aquele previsto nos programas das disciplinas escolares; a disponibilidade e utilização de materiais didáticos; a intervenção da direção, da coordenação e dos pais, entre outros tantos aspectos.

Diante dessa complexidade do trabalho pedagógico, acreditamos que o trabalho interdisciplinar de duas ou mais disciplinas escolares é um 
caminho para que o ensino e a aprendizagem se tornem experiências significativas para professores e alunos. Concebendo a interdisciplinaridade, acima de tudo, como princípio da diversidade e da criatividade, tal como propõe Etges (1995), os professores têm oportunidade de associar conhecimentos adquiridos em diferentes trajetórias acadêmicas para propor múltiplas abordagens dos conteúdos escolares, objetivando relacioná-los com as práticas sociais dos alunos.

Para trabalhar com Menino de engenho, na 7a série, construímos três eixos: "memória e criação literária", "o jogo temporal na tessitura da narrativa", "o conceito relações de trabalho no texto literário: dependência pessoal e prática do favor". Esses eixos foram propostos para análise dos alunos por meio da transposição didática, ou seja, da elaboração de materiais didáticos fundamentados no estudo da produção da crítica literária acerca da obra de José Lins do Rego e da produção sociológica a respeito das relações sociais no campo.

O eixo "memória e criação literária" foi analisado com base em estudos (Trigo, 2002; Villaça, 2003) que afirmam que, em Menino de engenho, o que unifica e integra os diversos episódios - além, é claro, da voz do narrador - é o próprio espaço físico e social, em que transcorre a ação. $\mathrm{O}$ espaço do engenho, que determina ações, emoções e pensamentos.

A narrativa entrecruza o espaço do engenho com o espaço interior. $\mathrm{Na}$ tentativa de resgate de outros tempos, José Lins do Rego se projetou inteiro no Carlinhos de Menino de engenho, entregando-se às reminiscências nostálgicas, à evocação de um paraíso perdido, identificando-se inteiramente com os valores e o modo de ser e de ver do menino.

Ao trabalharmos essas questōes com os alunos enfatizamos, entretanto, que quem narra Menino de engenho não é o menino Carlinhos, mas o homem Carlos de Melo, que, adulto, contempla e reconstitui, com certa melancolia nostálgica, o próprio passado. Daí a obra permitir a problematização do estatuto ficcional da memória: por ser reinventado pela imaginação e por obedecer ao tempo peculiar da memória, o mundo que Carlinhos visita não é o mesmo em que Carlinhos viveu. Pois, como afirma Montenegro (apud Trigo, 2002, p. 165), José Lins não evoca somente pela memória, mas "com o auxílio da imaginação", "menos como quem recorda do que como quem recria e alonga o passado no presente".

A questão da voz narrativa é de importância visceral para qualquer avaliação da obra de José Lins do Rego, pois ele cria uma voz narrativa 


\section{RevistaSoltaa Voz, v. 17, n. 2}

poderosamente autêntica, que se estenderá por outros romances, voz que é a chave para se entender a vida e o universo ficcional do escritor.

$\mathrm{O}$ autor transforma a si próprio em personagem em Menino de engenho, o que é óbvio. O que não é tão óbvio é que ele se transforma duplamente: no menino Carlinhos, a quem acompanhamos o tempo inteiro, e no adulto Carlos de Melo, narrador quase transparente, de cuja existência tendemos a nos esquecer.

Uma característica marcante do romance é a reconstituição que Carlos de Melo faz da infância de Carlinhos. Momento em que a ficção dialoga com as memórias de José Lins do Rego.

A infância guiada por forças poderosas que ele não entende é um tema recorrente na narrativa do Menino do engenho. O mundo da infância de José Lins, como o de Carlinhos, foi um mundo de menino enjeitado, de solidão, sofrimento e angústia. Sem falar nas coincidências nos dramas dos dois meninos: os tormentos da saúde, a ausência da mãe, os destemperos do sexo, o complexo de renegado - "tristezas que não deviam ser as de um menino" (Trigo, 2002).

Por isso, nas discussões e atividades propostas, incitamos a percepção da construção da infância de Carlinhos, tal como realizada pelo adulto Carlos de Melo na escrita da memória. Tais atividades se configuraram da seguinte forma:

1) Ao longo da narrativa, sentimentos experimentados por Carlinhos diante da vivência de diversos episódios vão compondo a sua vida interior.

a) Transcreva, do livro, pelo menos cinco trechos em que Carlos de Melo rememora alguns episódios que marcaram sua infância.

b) Identifique os sentimentos vivenciados por Carlinhos nesses episódios.

2) Componha a trajetória de Carlinhos a partir das lembranças que você considera as mais marcantes para a construção da infância sob a perspectiva do narrador.

3) Transcreva passagens da narrativa nas quais Carlos de Melo rememora a morte da mãe e a loucura do pai. Analise os significados desses acontecimentos para Carlinhos. (Atividade "Memória e criação literária")

"O jogo temporal e a tessitura da narrativa" foi um eixo analisado com base na concepção de que a construção do tempo como elemento estrutural da narrativa constitui característica fundamental dos romances 
que combinam memória e ficção para a composição da trama. O presente do autor e suas lembranças do passado se mesclam aos aspectos ficcionais para tecer a trajetória autobiográfica do narrador.

$\mathrm{Na}$ narrativa de Menino de engenho, a produção do passado de Carlinhos ocorre a partir do presente de Carlos de Melo. Ao mesmo tempo, percebe-se a permanência desse passado marcando a vida do narrador. Tais efeitos só são possíveis por meio de um complexo jogo temporal estabelecido pelo autor, que trabalha os tempos verbais como recurso lingüístico para a composição do texto literário.

A evolução cronológica da narrativa desse romance é sutil. Com uma referência aqui, outra ali, o narrador vai registrando o passar dos anos sem grandes saltos, de forma que o Carlinhos de quatro anos está em perfeita sintonia com Carlinhos aos doze anos. Une-os, naturalmente, a voz do Carlos de Melo, que revisita a si mesmo em diversas idades. $\mathrm{O}$ adulto anda de mãos dadas com o menino e depois com o adolescente, mas a voz que prevalece é a dele. Carlinhos, portanto, não se apresenta ao leitor tal como viveu na infância, mas contaminado e modificado pela visão do adulto memorialista (Trigo, 2002).

A construção das memórias não é fundamentada numa rígida seqüência cronológica, pois é a importância das lembranças na constituição subjetiva da infância que determina o desenrolar da trama. Além disso, há núcleos que concentram uma carga tão grande de significados que são recorrentemente lembrados, como, por exemplo, a morte da mãe e a loucura do pai.

A fim de trabalharmos essas complexas questóes em sala de aula, elaboramos um texto didático que permitisse aos alunos retomar o texto literário atento para o uso dos tempos verbais e outras estratégias de construção do tempo ao longo da narrativa de Menino de engenho. Ao mesmo tempo, propusemos uma reflexão a partir de uma série de questões:

Para compreender o jogo temporal na tessitura da narrativa, vamos retornar ao primeiro trabalho de leitura de Menino de engenho, quando analisamos a construção do tempo. Por meio das passagens indicadas nessa atividade e discutidas em aula, aponte o tempo verbal que o autor utiliza para:

a) construir a infância de Carlinhos;

b) demonstrar que o narrador é o adulto Carlos de Melo;

c) mostrar a permanência do passado marcando a vida do narrador. (Atividade "O jogo temporal e a tessitura da narrativa") 


\section{RevistaSoltaa Voz, v. 17, n. 2}

Vamos relacionar o estudo da temática sexualidade com a discussão sobre a importância do jogo temporal na narrativa de Menino de engenho. Observe esse aspecto nos trechos abaixo:

"Nós tínhamos, porém, no curral pegado à casa-grande, uma aula pública de amor. O que Zé Guedes nos contava dele com as Zefas, os touros e as vacas nos faziam entrar pelo entendimento. Era ali um bom campo de demonstração. Nos cercados dos engenhos o menino se inicia nestes mistérios do sexo, antecipando-se por muitos anos no amor. [...]" (cap. 15)

"Num dia em que ele me deixou sozinho, corri sôfrego para o objeto da proibição; uma coleção de mulheres nuas, de postais em todas as posições da obscenidade. [...]

[...] o meu tio pegou-me de surpresa com o pacote na mão. Botou-me para fora do seu quarto. Eu não era digno da sua intimidade, dos segredos da sua alcova." (cap. 30)

"A minha primeira paixão tinha sido pela bela Judite, que me ensinara as letras no seu colo. O meu coração de oito anos agora se arrebatava com mais violência. [...]

Para mim, a visita viera me aperrear o coração de menino. Maria Clara, mais velha do que eu, andava comigo pela horta. Menina da cidade, encontrara um bedéquer amoroso para mostrar-lhe os recantos do Santa Rosa." (cap. 34)

"Tinha uns 12 anos quando conheci uma mulher como homem. Andava atrás dela, beirando a sua tapera de palha, numa ânsia misturada de medo e de vergonha. Zefa Cajá era a grande mundana dos cabras do eito. Não me queria. - Vá se criar, menino enxerido." (cap. 39)

Identifique as duas estratégias utilizadas pelo autor para marcar a passagem do tempo e relacione com o amadurecimento da sexualidade de Carlinhos. (Atividade "Síntese")

Componha a trajetória de Carlinhos a partir das lembranças que você considera as mais marcantes para a construção da infância sob a perspectiva do narrador. (Atividade "O jogo temporal e a tessitura da narrativa")

Transcreva passagens da narrativa nas quais Carlos de Melo rememora a morte da mãe e a loucura do pai. Analise os significados desses acontecimentos para Carlinhos. (Atividade "O jogo temporal e a tessitura da narrativa”)

Para a análise do último eixo proposto, "o conceito relaçôes de trabalho no texto literário: dependência pessoal e prática do favor", foi preciso adaptar um estudo sobre a sociologia do mundo rural brasileiro (Vita, 1994). 
Nas discussões realizadas em sala de aula, construídas a partir de questôes que problematizavam a leitura individual dos alunos, foi possível enfatizar que, no livro Menino de engenho, o engenho Santa Rosa é a unidade de produção em torno da qual se constrói a vida das personagens. Nele encontramos o coronel José Paulino comandando ex-escravos, agregados, arrendatários, sitiantes, parentes e afilhados, sem que nada limite o seu poder. Com isso, foi possível problematizar o conceito de permanência nas relações de trabalho, pois os alunos observaram que as condiçôes de vida dos ex-escravos, em Menino de engenho, não eram muito diferentes das condiçōes dos escravos, em A escrava Isaura.

Essas relações de trabalho diversas que se combinam nessa propriedade agrícola só podem ser compreendidas considerando que a escravidão havia sido abolida há poucos anos. Assim, a característica comum nessas relações de trabalho é a permanência da dependência entre os trabalhadores que não têm acesso à terra e o latifundiário.

No período em que o Brasil era uma sociedade escravista, nas relações entre senhores e escravos, a violência era por demais evidente para poder ser ocultada ou atenuada. $\mathrm{O}$ escravo era uma mercadoria possuída pelo fazendeiro e trazia em seu próprio corpo as marcas de sua sujeição. Já entre os homens livres, as relaçôes de dominação eram bem mais complexas e menos visíveis - embora a violência da imposição da vontade do mais poderoso não fosse, talvez, menor. Como a propriedade da terra estava concentrada nas mãos de poucos, a maior parte da população submetia-se a diferentes condições de exploração para garantir sua sobrevivência.

A forma como ocorreu a colonização no Brasil determinou o surgimento de dois setores econômicos diversos, mas que coexistiram no interior da grande propriedade rural: a produção de mercadorias para o mercado e um setor de subsistência, que produzia alimentos, com base no trabalho familiar de agregados, arrendatários e sitiantes (que, apesar de pequenos proprietários, não escapam da órbita de influência do latifúndio).

Mesmo com a abolição da escravidão e a proclamação da república, período representado no livro Menino de engenho, as relações de trabalho no campo são marcadas pela permanência da dependência entre aqueles que não possuem terra e os grandes latifundiários, que dominam também a política na região - os chamados coronéis, como o coronel José Paulino. 


\section{RevistaSoltaa Voz, v. 17, n. 2}

No engenho Santa Rosa há ex-escravos, homens pobres que têm acesso a uma pequena porção de terra em troca da prestação de serviço: são os agregados. Também há o arrendatário que paga pelo uso da terra em produtos. Por último, os sitiantes que, mesmo sendo proprietários de pequenas porçōes de terra próximas ao engenho, mantêm relaçõos de dependência com o coronel. Os alunos foram incitados a encontrar e registrar toda essa rede complexa de relações de trabalho no interior do engenho Santa Rosa, pois propusemos a seguinte atividade:

1) Cite exemplos que caracterizem cada uma das diversas relações de trabalho e de propriedade da terra observadas na leitura do Menino de engenho: ex-escravos, agregados, arrendatários e sitiantes.

2) A partir de situaçōes verificadas na trama, descreva as diversas relaçōes de dependência e troca de favores entre o coronel e os homens pobres. (Atividade "Relações de trabalho no Engenho Santa Rosa")

Essas relaçóes que uniam os homens pobres ao coronel eram baseadas no compromisso de caráter pessoal que prendiam - e sujeitavam - os ex-escravos, agregados, arrendatários e sitiantes ao coronel. Fundamentados em valores morais compartilhados por um e outro, tais como fidelidade e lealdade, esses compromissos exigiam de ambas as partes uma contínua prestação de favores, assim como uma permanente retribuição dos favores recebidos. Era a prática do favor, portanto, que articulava as relaçôes entre senhores de engenho e os homens pobres.

O agregado mantinha sua posse em terras do senhor e dependia do favor deste último para conservá-la. Para o dominado, sua própria sobrevivência era uma dádiva do mais poderoso, que deveria ser recebida com gratidão. "Favor com favor se paga", essa era a norma. O agregado, por sua parte, estava obrigado a retribuir o favor recebido de muitas maneiras diferentes: prestando ao fazendeiro trabalho gratuito ou em troca de uma remuneração insignificante; pegando em armas para defender o seu senhor em lutas pela terra e ainda votando nas eleições nos candidatos indicados pelo fazendeiro. Em determinados momentos, também os arrendatários e os sitiantes prestavam favores diversos ao coronel, pois dependiam da sua proteção.

É preciso ressaltar ainda que a autoridade do latifundiário não se mantinha apenas por sua posição social ou pelo uso da violência: o dominado reconhecia essa autoridade como legítima. O que ganhavam os 
homens pobres em manter tal situação? A explicação vem do tempo da escravidão. Além da necessidade de sobrevivência, essas relaçõos de dependência dos homens livres em relação ao latifundiário têm origem na sociedade escravocrata. O favor assegurava às duas partes, em especial à mais fraca, que nenhuma era escrava. Mesmo o mais miserável dos favorecidos via reconhecida nele, no favor, a sua pessoa livre. Ou seja, a prática do favor estabelecia-se entre partes que se reconheciam mutuamente como pessoas - nenhuma era escrava.

Para que os alunos percebessem a dinâmica das relações de favor no cotidiano do engenho Santa Rosa, elaboraram-se as seguintes questões que, depois de discutidas em sala de aula, foram objeto de produção escrita dos alunos:

1) A partir da leitura dos capítulos 16 e 32, no contexto da narrativa Menino de engenho, produza um texto em que você:

a) descreva e analise o papel do coronel José Paulino em relação a sua propriedade e aos trabalhadores que nela atuam de diferentes formas;

b) discuta as consequiências do passado escravista percebidas nas condições de trabalho e de vida dos trabalhadores do engenho;

c) estabeleça diferenças entre as visōes que "Carlinhos" (último parágrafo do capítulo 32) e "Carlos de Melo" têm sobre esses trabalhadores. (Atividade "Síntese")

Após a análise e a discussão coletiva de cada um desses eixos, essas propostas de exercícios individuais de interpretação escrita possibilitaram ao aluno expressar os significados e sentidos que construiu para o livro que leu. Reconhecemos, no entanto, como Nunes, que

O texto "não pode ser percebido num só tempo", assim como percebemos um quadro. Mas essa percepção temporal, a modo de um percurso, também é um trabalho de imaginação; não só porque o leitor preenche a significação das frases e esquemas, mas sobretudo porque preenche as lacunas, os brancos, os pontos de indeterminação do texto, sem que jamais se feche o seu sentido quando o capta, sentido que outro leitor captará mais tarde, com variaçōes decorrentes de suas próprias vivências (Nunes, 1999, p. 199).

Com base nessa compreensão da leitura, procuramos criar a possibilidade de o aluno registrar suas percepções pessoais, levantando os seguintes aspectos para reflexão e conseqüente produção escrita: 


\section{RevistaSoltaa Voz, v. 17, n. 2}

A partir de sua experiência como leitor, selecione uma das passagens do livro que represente a construção da sexualidade masculina e construa um comentário, destacando suas impressões. (Atividade "Síntese")

No livro Menino de engenho, a narrativa das memórias de infância foram reconstruindo de forma subjetiva os principais acontecimentos que compõem o enredo. A partir da sua leitura e das discussóes feitas em aula, produza um texto em que você trace o perfil psicológico de Carlinhos. (Atividade "Memória e criação literária")

A nossa trajetória de professoras e pesquisadoras tem nos permitido avaliar como produtiva, para a produção de leitura e do conhecimento pelo aluno, a interdisciplinaridade entre Português e História, especialmente no trabalho com a literatura, justamente por considerar, conforme Perrone-Moisés (1983, p. 50), que "ler não seria aplicar modelos prévios, mas criar formas únicas, que são formas virtuais do texto ativadas pela imaginação do leitor". Pretendemos, assim, além de estimular os alunos a refletir sobre as múltiplas relações entre memória e literatura, suscitar que cada aluno-leitor possa exercitar seus próprios itinerários de interação com as obras literárias.

\section{REFERÊNCIAS}

BOSI, E. O tempo vivo da memória. Ensaios de psicologia social. São Paulo: Ateliê Editorial, 2003.

CALVINO, I. Por que ler os clássicos? São Paulo: Companhia das Letras, 1997.

CERTEAU, M. de. A invenção do cotidiano: artes de fazer. Petrópolis, RJ: Vozes, 1994.

CERTEAU, M. de.; GIARD, L.; MAYOL, P. A invenção do cotidiano: morar, cozinhar. Petrópolis, RJ: Vozes, 1996.

CHERVEL, A. História das disciplinas escolares: reflexões sobre um campo de pesquisa. Teoria \& Educação, Porto Alegre, v. 2, 1990, p.177-229.

CHEVALLARD, Y. La transposición didáctica: Del saber sábio ao saber ensenãdo. Argentina: Aique Grupo Editor AS, 1991. 
DELGADO, A. F. A invenção de Cora Coralina na batalha das memórias. Tese (Doutorado em História). Instituto de Filosofia e Ciências Humanas da Universidade Estadual de Campinas, Campinas, SP, 2003.

ETGES, N. J. Ciência, interdisciplinaridade e educação. In: JANTSCH, A. e BIANCHETTI, L. (Orgs.). Interdisciplinaridade: para além da filosofia do sujeito. Petrópolis, RJ: Vozes, 1995. p. 51-84.

GUIMARĀES, B. A escrava Isaura. São Paulo: Editora do Brasil, 2000.

HUNT, L. (Org.). A nova história cultural. São Paulo: Martins Fontes, 1992.

LARROSA, J. Pedagogia profana: danças, piruetas e mascaradas. Belo Horizonte: Autêntica, 2000.

LE GOFF, J. ( Org.). A história nova. São Paulo: Martins Fontes, 1990.

NUNES, B. Ética e leitura. In: BARZOTTO, H. V. (Org.). Estado de Leitura. Campinas, SP: ALB - Mercado de Letras, 1999. p. 193-205.

PERRONE-MOISÉS, L. Roland Barthes. São Paulo: Brasiliense, 1983.

REGO, J. L. do. Menino de engenho. Rio de Janeiro: José Olympio, 2003.

Doidinho. Rio de Janeiro: José Olympio, 1994.

TRIGO, L. Engenho e memória: o nordeste do açúcar na ficção de José Lins do Rego. Rio de Janeiro: Topbooks, 2002.

VILLAÇA, A. C. Menino de engenho. In: REGO, J. L. do. Menino de engenho. Rio de Janeiro: José Olympio, 2003. p.19-27.

VITA, A. de. Sociologia da sociedade brasileira. São Paulo: Ática, 1994.

Recebido em: 15 set. 2006

Aceito em: 7 nov. 2006 